\title{
Feasibility Study of Compaction and Sintering of Commercially Pure Titanium using Friction Stir Processing
}

\author{
Aleksandra Fortier"**, Nilesh Kumar^, Mageshwari Komarasamy!, Rajiv S. Mishra! \\ \#Mechanical and Energy Engineering Department, College of Engineering, University of North Texas, Denton, TX 76207, USA \\ ${ }^{\wedge}$ Department of Nuclear Engineering, College of Engineering, North Carolina State University, Raleigh, NC 27695, USA \\ !Department of Materials Science and Engineering, College of Engineering, University of North Texas, Denton, TX 76207, USA
}

Received 15 March 2018, Accepted 18 May 2018, Available online 22 May 2018, Vol.8, No.3 (May/June 2018)

\begin{abstract}
Manufacturing of a component through powder metallurgy (PM) route involves at least three critical steps: powder blending, compaction, and sintering. Overall, the PM route takes 4 to 8 steps to get to the final product. Moreover, it requires a huge amount of capital investment to perform every step of the manufacturing process via PM route. Friction stir processing (FSP) is a derivative of friction stir welding which has emerged as a generic microstructural modification tool in last one decade. The aim of the current work was to explore the possibility of decreasing the number of steps required in the manufacturing of a product using the PM technique. Using the FSP method, the manufacturing process is reduced to two steps and the mechanical properties of the final product are significantly improved. In this study, commercially pure titanium (Ti) powder was used. The two-step process appeared extremely efficient and it involved: 1) constraining the Ti-powder in a die and using a punch to consolidate it in a final disk-like geometry, 2) next, the consolidated disk-shaped product was processed using FSP tool and methods. Initial mechanical characterization results show peak hardness of the FSP processed Ti-powder product to be approximately $436 \mathrm{HV} 0.3$ with average hardness measured at about $251 \mathrm{HV}$. The electron backscattered diffraction of the FSP-assisted sintered region showed equiaxed grains with average grain size to be $440 \pm 254 \mathrm{~nm}$. The initial result indicates FSP can be used as a manufacturing tool for consolidating powders in to bulk solid form.
\end{abstract}

Keywords: Ti powder, sintering, green manufacturing, friction stir processing, powder metallurgy, cold compression.

\section{Introduction}

Converting Ti from the raw minerals to aeronautical Ti-grade usually takes many processing steps and up to a period of six months [http://www.britannica.com/ science/titanium]. Most of $\mathrm{Ti}$ is found in titanium ore in beach sand minerals named rutile, ilmenite, and leucoxene (S.M. El-Soudani, 2015; https:// www.youtube.com/ titanium). Once extracted and separated via a wet mill, the Ti-ore is transported for purification. One way to remove most of Ti from its ore is through Kroll Process [C. Doblin, 2013]. The pure Ti is in sponge powder form and it is processed further using ingot production processes and purity tests (C. Doblin, 2013). The powder is converted into an ingot of usable quality by compression, welding, and multi iteration melting in a vacuum-equipped furnace (G. M. D. Cantin et al., 2011 - K. A. Gogaev et al., 2009). Other usable forms such as $\mathrm{Ti}$ - sheets are made from rods which are heated to approximately two-thirds of the

*Corresponding author's ORCID ID: 0000-0001-7612-6572 Email: drafortier@gmail.com

DOI: https://doi.org/10.14741/ijcet/v.8.3.15 melting point of $\mathrm{Ti}$ then mechanically pressed for several hours, followed by cutting and polishing giving Ti-product ready for application (W. J. Kim et al., 2011; X. Huang et al., 2010). The flowchart shown in Figure 1 summarizes steps involved in the processing of $\mathrm{Ti}$ powder in to bulk solid form using powder metallurgy (PM) technique.

Due to growing concern over human-activities related adverse environmental impact, new and innovative manufacturing techniques are being developed adding new dimensions to the design and development of materials and engineering components. Friction Stir Processing (FSP), a derivative of friction stir welding invented at The Welding Institute, UK in 1991, has been has proven to be such a technique that has been envisioned to have a variety of potential applications (R. S. Mishra et al. 2014). In its simplest form, this process involves use of a non-consumable rotating tool (generally made of tool steel, refractory metals or ceramics) that can plunge in to a plate gradually to accomplish its intended goal ( $R$ S. Mishra et al., 2014). The entire process is carried out in solid-state. 


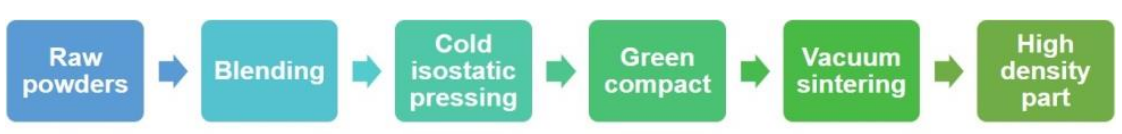

Figure 1 Flow chart showing traditional Ti production steps from powder to final product (S.M. El-Soudani, 2015)

Therefore, all the issues related to re-melting and solidification is avoided, and at the same time, all the beneficial effects of solid-state processing are retained. The term solid-state refers to a process that operates under the melting/solidus point of a material to improve mechanical properties. Processing parameters for FSP influence the properties of the processed region.

FSP has been used in a variety of applications microstructural modification, surface composites (R. S. Mishra et al., 2014 - Z. Y. Ma, 2008) , friction stir extrusion (W.T. Evans et al. 2015; W. T. Evans et al, 2017)to name a few. The focus of this study is to carryout a feasibility study on transforming powder to bulk solid form using FSP in a fewer steps than that involved in conventional PM technique. For feasibility demonstration, we have chosen Ti-powder to convert it into a final solid form. Although there are some attempts in the past to improve the process efficiency and productivity for the components manufactured using conventional PM route (S.M. El-Soudani, 2015), in our knowledge, this is first of its kind study which uses FSP techniques for transforming metallic powder form in to a bulk solid form. This was done by two-step process involving: 1) constraining the Ti-powder in a die and using a punch to consolidate it in a final disklike geometry, 2) next, the consolidated disk-shaped product was processed using FSP. Figure 2 shows flowchart of the proposed method tested in this study. The proposed manufacturing method may have bearing on cost and energy usage by reducing manufacturing steps from 4-8 to only 2 . If our current approach is successful, we will be able to eliminate powder mixing step and mechanical pressing step (Figure 2) will be less demanding in comparison with cold-isostatic pressing (Figure 1) due to high forging force present during FSP step.

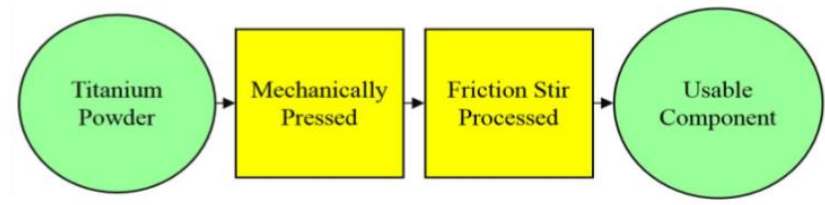

Figure 2 Flow chart showing two-step process for Tipowder proposed and tested in this study.

\section{Experimental methods}

\subsection{Materials}

Two types of Ti-powders were studied for comparison. The first Ti-powder supplied by Puris, LLC was classified as 99.835 wt.\% CP titanium, spherical powder grade 1 , -60 mesh $(90 \%$ particles $<250 \mu \mathrm{m})$, with the compositional breakdown shown in Table 1. The second Ti-powder was received from Materials and Electrochemical Research Corporation (MER Corp.) and was classified as $99.5682 \%$ hydride/dehydride titanium sponge powder, +100 mesh $(90 \%$ particles $>150 \mu \mathrm{m})$ with the compositional breakdown also shown in Table 1.

Table 1: Chemical composition of two Ti-powders used in this study

\begin{tabular}{|c|c|c|}
\hline Element & Ti (Puris), wt $\%$ & Ti (MER) wt $\%$ \\
\hline $\mathbf{A l}$ & 0.013 & $<0.005$ \\
\hline $\mathbf{F e}$ & 0.036 & 0.13 \\
\hline $\mathbf{N a}$ & 0.0005 & 0.001 \\
\hline $\mathbf{S i}$ & 0.0062 & $<0.01$ \\
\hline $\mathbf{Y}$ & $<0.0005$ & - \\
\hline $\mathbf{C u}$ & 0.0083 & - \\
\hline $\mathbf{S n}$ & 0.002 & $<0.005$ \\
\hline $\mathbf{O}$ & 0.083 & 0.069 \\
\hline $\mathbf{N}$ & $<0.005$ & $<0.0035$ \\
\hline
\end{tabular}

\subsection{Equipment Used}

\subsubsection{Die, Punch, and Press}

Stainless steel cylindrical die and punch, shown in Figure 3 were used in these experiments to consolidate the Ti-powder into enough green strength so that it can be processed by FSP next. The diameter and height of the compressed samples were $-10.0 \mathrm{~mm}$ and $6.35 \mathrm{~mm}$ respectively. The cylindrical die and punch was successful at compressing each powder by being comprised of one solid piece: the die body. The spacer in between the bottom die component was crucial for avoiding leaks of powder through the bottom. The clearance between the punch and the die body hole diameters was very tight thus making the two surfaces able to slide past each other without allowing powder leakage through the top of the die. Without corners, circular cross-sectional areas have the advantage of not having weaker stress points seen in shapes with corners. For compressing the samples, Carver manual hydraulic press was used throughout the experimental stages. The maximum compression capacity pressure of this press is $24,000 \mathrm{lbs}$ or 11 metric tons using a needle gauge. Once the press is pumped to the designated pressure, a time was set for every 5 minutes in a 30-minute period for checking and pumping back to the designated pressure to compensate for slippage and relaxation of the titanium powder. Figure 4 shows the resulting compacts compressed at 5,000 lbf and adjusted every 5 minutes 
in a 30-minute timed session. Note that, at compression stage, no binder or plasticizer was used as commonly used in PM technique.

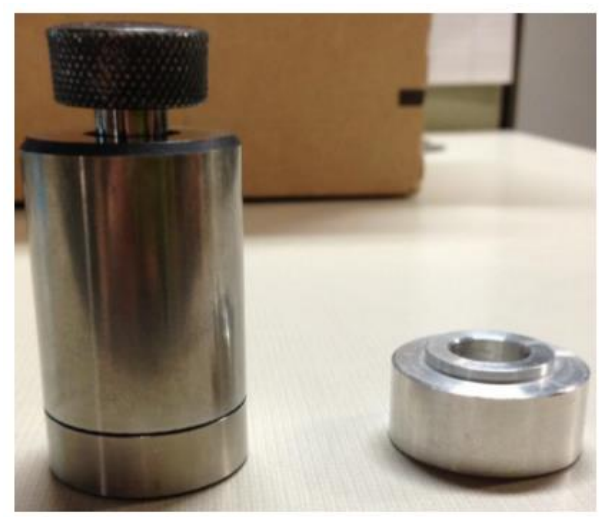

Figure 3 Left: assembled cylindrical die and punch, right: aluminum sample retriever spacer.
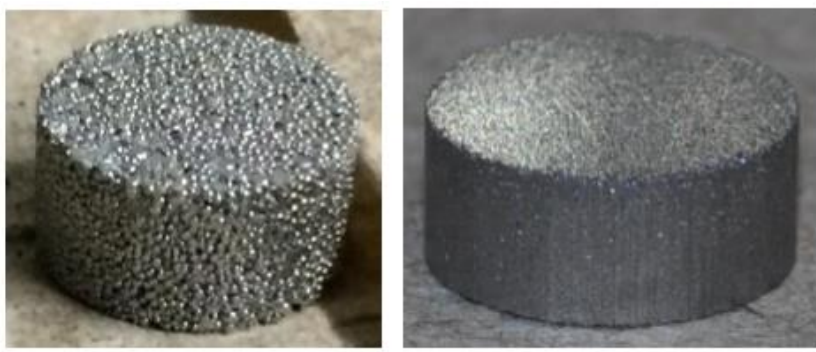

Figure 4 Left: larger particle spherical titanium compacted at 5,000 lbf using the manual hydraulic press, right: finer grained sponge titanium compacted at 5,000 lbf using the manual hydraulic press (the

height of the cylindrical compact: $\sim 6.35 \mathrm{~mm}$ ).

\subsubsection{Friction Stir Processing}

Small hole was milled on an AISI 1018 carbon steel block with dimensions $118.4 \mathrm{~mm}$ long $\mathrm{x} 152.6 \mathrm{~mm}$ wide $\times 25.03 \mathrm{~mm}$ high (to span the width of the FSP working table for convenience) for the FSP of compressed Ti-samples. The sample-holding hole had a diameter of $10.50 \mathrm{~mm}$ and a depth of $6.35 \mathrm{~mm}$ through the block to make a hole for a $3.02 \mathrm{~mm}$ diameter scrap titanium bar to fill the hole when processing and then another $25.60 \mathrm{~mm}$ long scrap titanium bar was used to hammer out the consolidated titanium from the bottom of the sample holder. Figure 5 shows pictures of the custom assembly. The sample was inserted into this hole and then friction stir processed at a $600 \mathrm{rpm}$ tool rotation rate, $0.5 \mathrm{~mm} / \mathrm{min}$ plunge speed, and $180 \mathrm{~s}$ dwell time. The plunge depth was varied depending on the sample height and plunging time gradient was added depending on the results. A retrieval hole is not milled out to avoid any powder leakage; retrieval involves cutting up the carbon block.

This approach is designed to give approximately 1.0 $\mathrm{mm}$ clearance of the tool diameter when plunging into this hole, as well as approximately a $2.0 \mathrm{~mm}$ climb for powder to escape, hopefully minimizing powder leakage. Cylindrical Ti- samples (-60 mesh) compressed at 5,000 lbf (shown in Figure 4) were used for this method of testing.

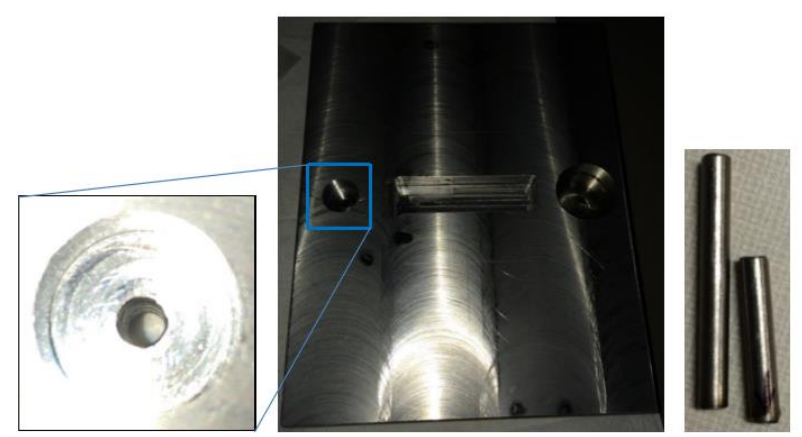

Figure 5 Left: zoomed in new cylindrical hole approach, middle: new sample holder block (note the hole on the right was a milling mistake), right: two scrap titanium bars used for planned sample retrieval.

The FSP tool used was D2M (W-Ni-Mo-Fe) tungsten alloy tool made for high-temperature applications and with a hardness higher than that of titanium. The tool used had the following geometrical details: diameter $10.4 \mathrm{~mm}$, height $9.5 \mathrm{~mm}$, base and tip diameter $4.1 \mathrm{~mm}$, pin base height and at edge shoulder height $2.05 \mathrm{~mm}$. Up to 10 different trial and error attempts were performed with various parameters and 3 identical samples per trial were processed. Here we will present analysis and results for only three samples which are representative of successful welds and they only differ by the tool plunge depths (see Figure 6 for successfully processed samples). The rest of the optimized parameters are same for all samples presented in this study.

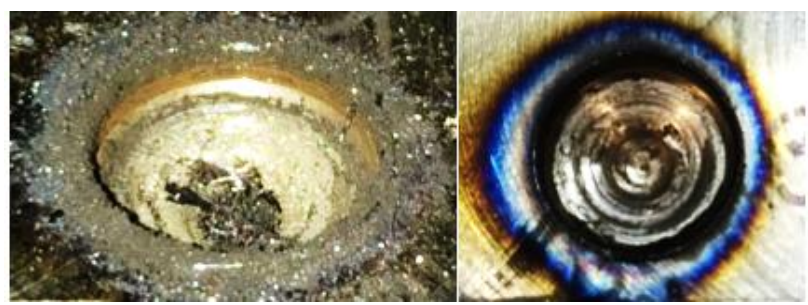

(a)

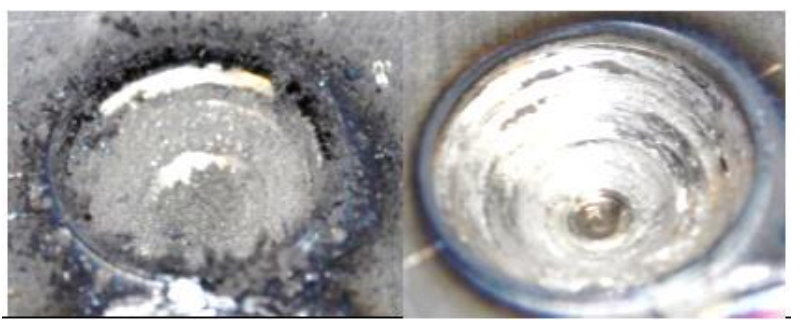

(b) 


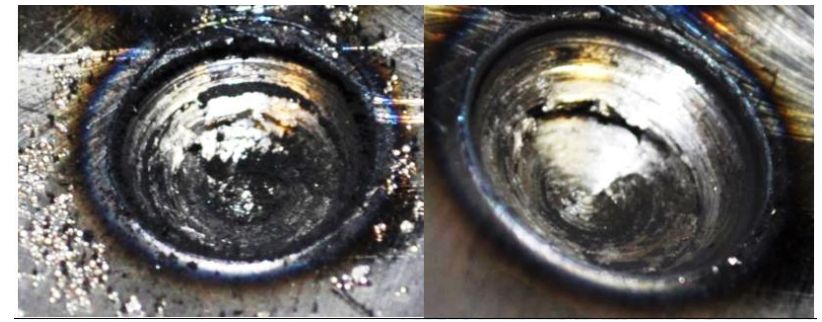

Figure 6 Left: before cleaning right: immediately after cleaning a) plunge depth $4 \mathrm{~mm}$ b) plunge depth $3.9 \mathrm{~mm}$ c) plunge depth $3.6 \mathrm{~mm}$

\subsection{Mechanical Testing and Microstructural Examination}

The three samples were milled down from the steel block and their cross-section was exposed for analysis. Figure 7 shows the cut cross-section for each sample. The samples were then ground with 600, 800, and 1200 silicon carbide metallurgical grinding paper with water then dried with pressurized air followed by polishing on chem-pol cloth with a solution of $0.05 \mu \mathrm{m}$ colloidal silica. Each sample was then immersed in ethanol and put into an ultrasonic cleaner for 5 minutes. The samples were removed from the ultrasonic cleaner and ethanol and quickly dried under pressurized air. Each sample was again cleaned by hand, swab, ethanol, and then dried by pressurized air at least three times. Figure 8 shows a schematic of the cross-sectional view shown in Figure 7.

The hardness data for each sample was collected using the Vickers micro-indentation hardness tester with $300 \mathrm{gf}$ force used on each sample for ten seconds. Sixteen hardness values were collected across the consolidated region for each sample including the die material, 1018 carbon steel. Each hardness test taken was estimated to be in the middle of the consolidated region (Region A, Figure 8). This number of hardness tests taken has exceeded the required number of five hardness tests taken for the ASTM Handbook for Validity of Mechanical Testing (ASTM Handbook for Validity of Mechanical Testing, 2017). Nearly pure titanium should have a Brinell hardness of 200 which is between 210 and 220 Vickers hardness (C. Doblin et al., 2013) . While multiple grades of commercially pure titanium should have a Vickers hardness of 145 (C. Doblin et al., 2013).

Scanning Electron Microscope (SEM), Energy Dispersive Spectroscopy (EDS) and Electron Backscattered Diffraction (EBSD) analyses were carried out to get microstructural information on the samples processed using FSP. The sample preparation for microstructural examination was as described for the sample prepared for microhardness measurement. However, for the EBSD, final polishing was done on VibroMet ${ }^{\mathrm{TM}}$ polisher using $0.05 \mu \mathrm{m}$ colloidal silica for about $15 \mathrm{~h}$. The region A shown in Figure 8 was analyzed for each sample to obtain microstructural information.
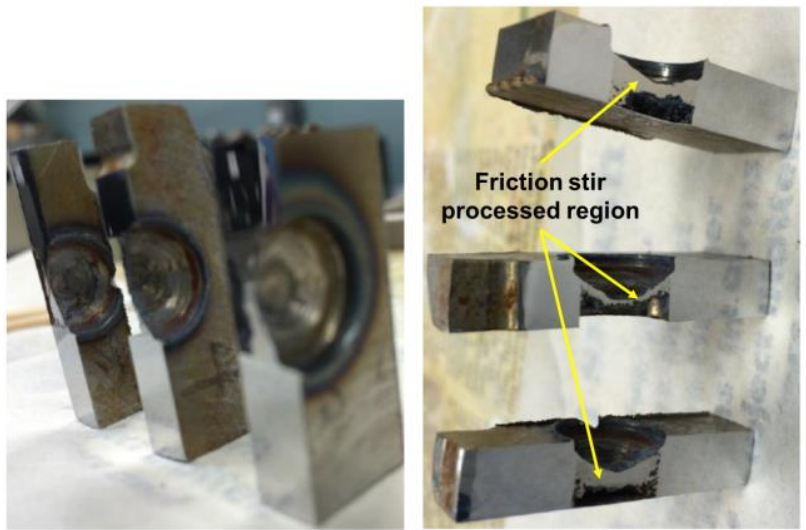

Figure 7 Left: samples 1 through 3 left to right seen from top view, right: samples 1 through

3 top to bottom seen at cross-sectional view

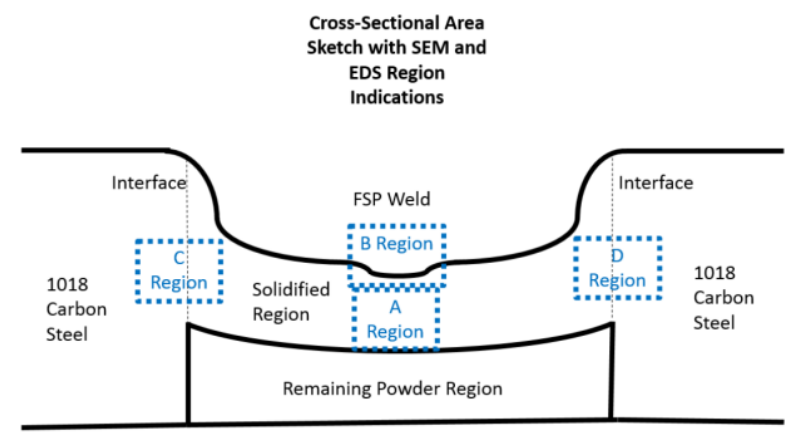

Figure 8 - Schematic showing the cross-sectional region $\mathrm{A}$ that was analyzed for each sample

\section{Results and Discussions}

\subsection{Consolidation of the Ti-powder using FSP}

In general, during FSP of an alloy, intense heat is generated as a result of friction between the rotating FSP tool and the material being processed, and also, a part of the heat also comes from severe plastic deformation of the material (R. S. Mishra et al., 2014). The heat generated during the processing raises the temperature of the material to the extent it becomes easier for the tool to move from one side of the tool to another side. In the present case, the friction between the rotating tool and the Ti-powder and intense plastic deformation at very high rate of the powder result in frictional and adiabatic heat which causes temperature of the powder being processed to rise. Although no thermal measurement during the process was carried out, the literature on the FSP of Ti and its alloys suggest that the temperature could reach as high as $1500^{\circ} \mathrm{C}(\mathrm{R}$. S. Mishra et al., 2014). In addition to this, the FSP tool exerts a very high forging force on the material being processed. It, therefore, appears that very high temperature and forging force acting on the powder may have caused accelerated sintering of the coldcompacted Ti-powder. 


\subsection{Microhardness}

Figures 9 to 11 report microhardness distribution for samples 1 (plunge depth $4.0 \mathrm{~mm}$ ), sample 2 (plunge depth $3.9 \mathrm{~mm}$ ), and sample 3 (plunge depth $3.6 \mathrm{~mm}$ ), respectively. The averages of the titanium region of each sample's hardness is 245, 201, and 307 HV0.3 for samples 1, 2, and 3 respectively. The trend seems to be that in the thickest part of each sample, there is a significant spike of hardness that averages to be 418 and 409 HV0.3 for samples 1 and 3 respectively. Regardless, both samples 1 and 3 either met or exceeded the literature source for hardness data of bulk titanium (C. Doblin et al. 2013; http://www.engineershandbook.com/Tables/hardnes s) . This proves that the friction stir processing not only consolidated the titanium powder but also improved its hardness properties which makes it probable that other mechanical properties such as tensile strength has also improved. The variation in hardness values across the width of the sintered powder may be a result of microstructural variability along the width. At the center of the processed region temperature is found to be maximum during FSP. It may result in better consolidation of the powder at the center in comparison with the outer region. However, this situation can be mitigated by improving the tool design and optimizing the processing parameters that requires further exploration.

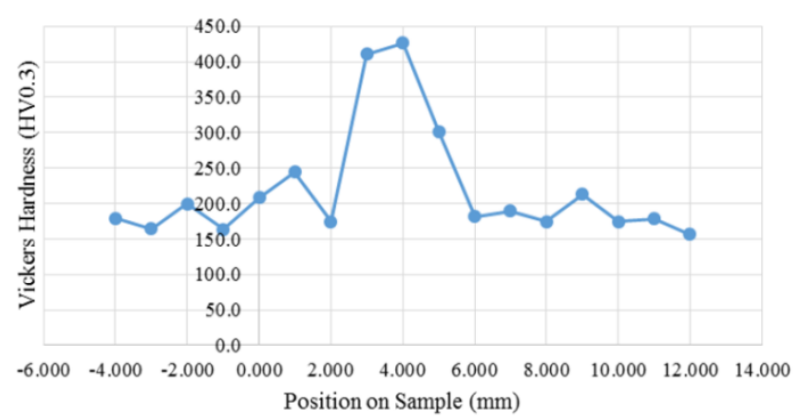

Figure 9 Hardness distribution for sample\#1 with plunge depth of $4 \mathrm{~mm}$

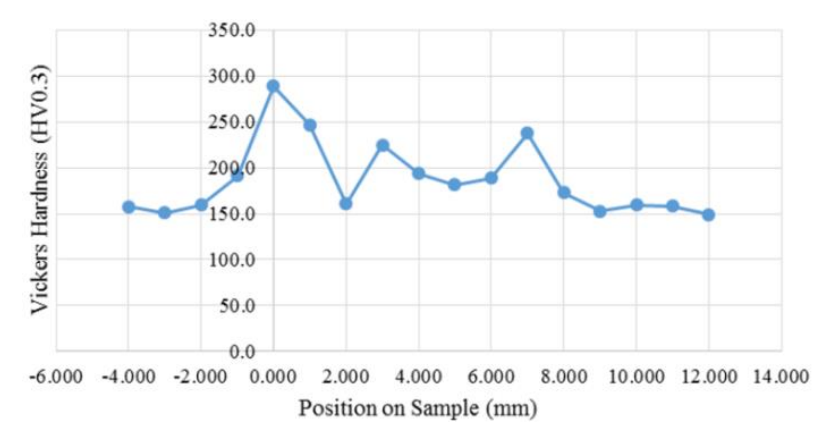

Figure 10 Hardness distribution for sample\#2 with plunge depth of $3.9 \mathrm{~mm}$.

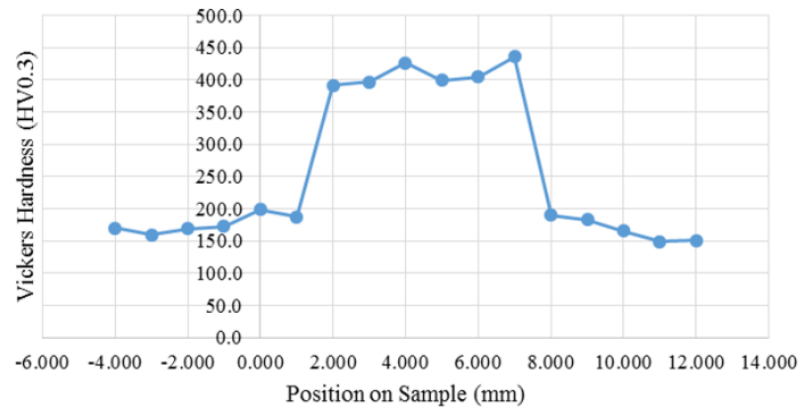

Figure 11 Hardness distribution for sample\#3 with plunge depth of $3.6 \mathrm{~mm}$

\subsection{SEM and EDS Analysis}

Surface topography of the Ti-powder ( -60 mesh) compacted using compression fixture was observed under optical microscope just for comparison to the samples that were friction stir processed. Figure 12 shows micrograph of compacted Ti-powder before FSP. The gap between the particles suggest that the compaction can be further improved by increasing the compaction pressure to achieve higher green density of the compacted powder.

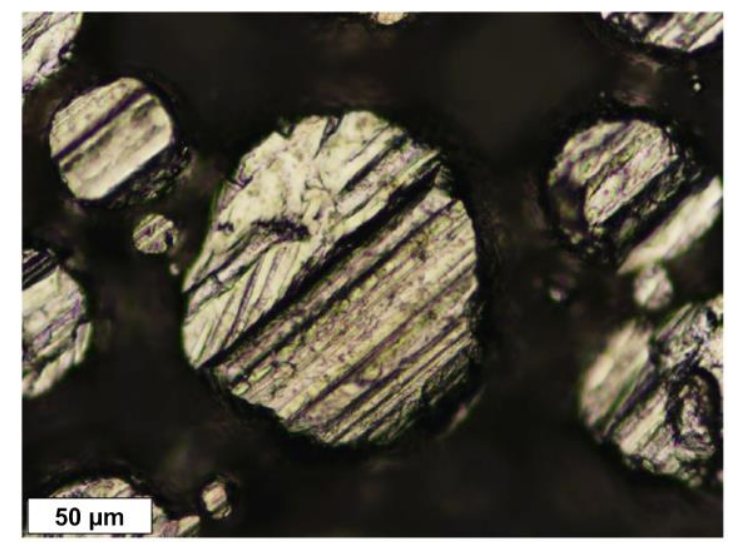

Figure 12 Micrograph showing topography of compacted Ti-powder before FSP

Figure 13 shows SEM and EDS for sample 1, the consolidated powder section is approximately 1-2 mm thick and be distinguished by the dark uniform area sandwiched between the bright region (top) and the disorganized clumpy area (unconsolidated powder area towards the bottom). In region B, the FSP edge can be seen at the top of the image while the consolidated titanium area consumes most of the image. Overall the mixing of the titanium is good with a clean interface. The EDS profile (Figure 13c confirms Ti presence). For sample 2 (Figure 14) the consolidated powder section seen in region $A$ is approximately less than $1 \mathrm{~mm}$ thick but is marginally shallower than sample 1 making it the most shallow sample out of all three, this may account for the hardness staying below 300 HV0.3. Sample 2 also shows a less defined interface separation 
between the titanium powder and the carbon steel die. EDS image (Figure 14c confirms $\mathrm{Ti}$ presence). In sample 3 (Figure 15), all regions are distinguished in relatively the same manner as sample 1 and 2. The consolidated powder section seen in region $\mathrm{A}$ is approximately $2 \mathrm{~mm}$ thick making it the deepest consolidated region of all three samples correlating to the highest peak hardness values for most of the sample length than any of the samples. There is relatively clean interface between the carbon steel die and the consolidated titanium powder, however, side regions show evidence of mixing. The EDS profile (Figure 15c) confirms the presence of Ti. Compared to the OM image (Figure 12), every sample was successfully consolidated with FSP.

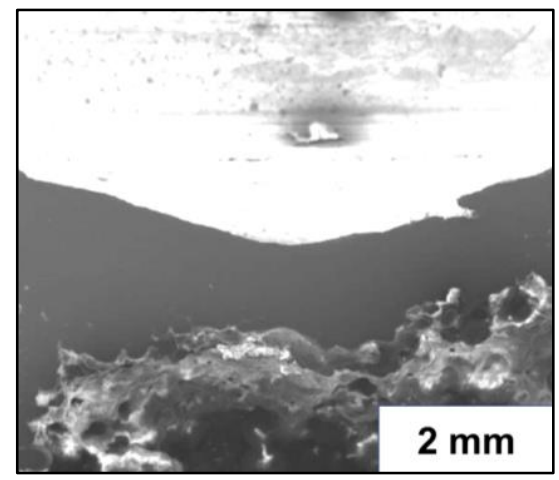

(a)

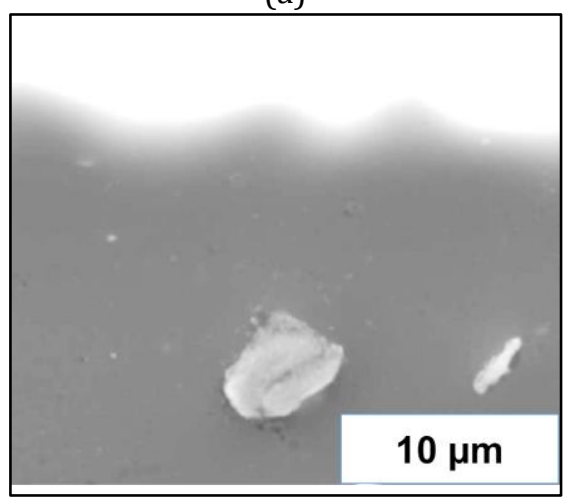

(b)

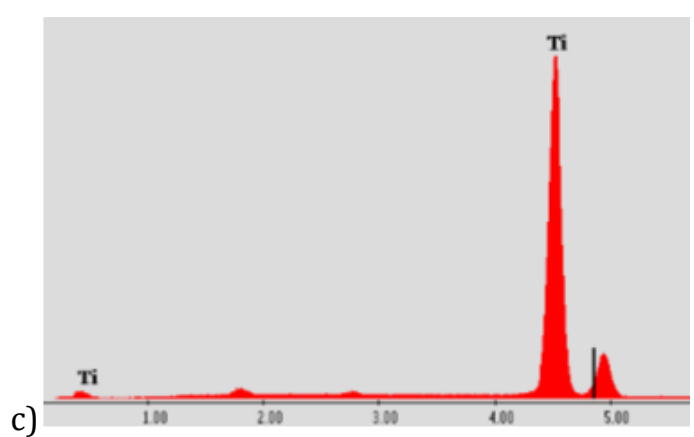

(c)

Figure 13 - Sample 1: a) a low magnification SEM image of region $A$ and $B$ b) a high magnification SEM image of region A c) EDS analysis confirming the presence of $\mathrm{Ti}$ in the consolidated region

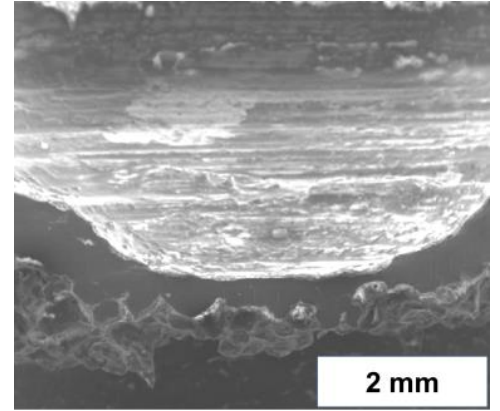

(a)

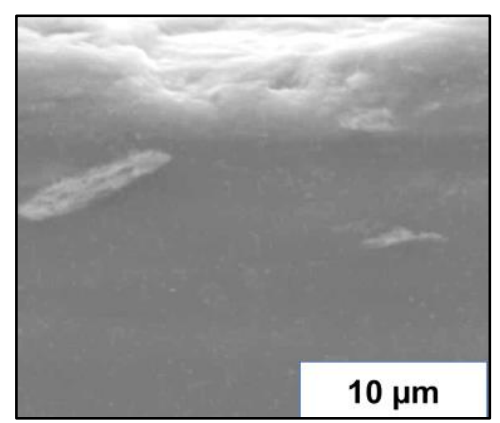

(b)

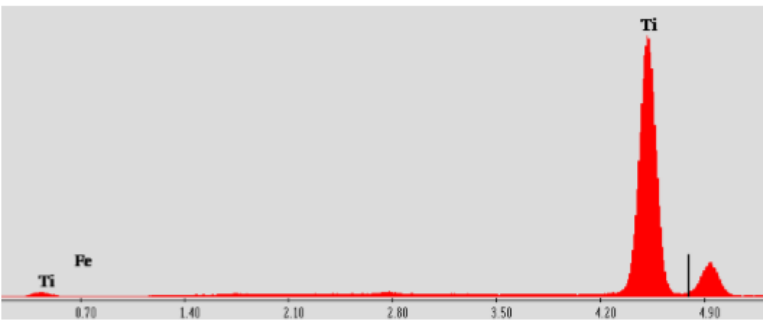

Figure 14 Sample 2: a) a low magnification SEM image of region $A$ and $B$ b) a high magnification SEM image of region A c) EDS analysis confirming the presence of Ti in the consolidated region

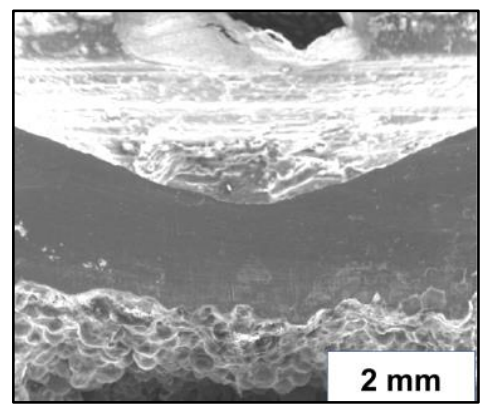

(a)

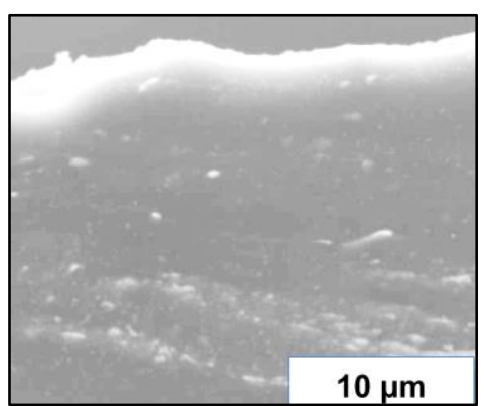

(b) 


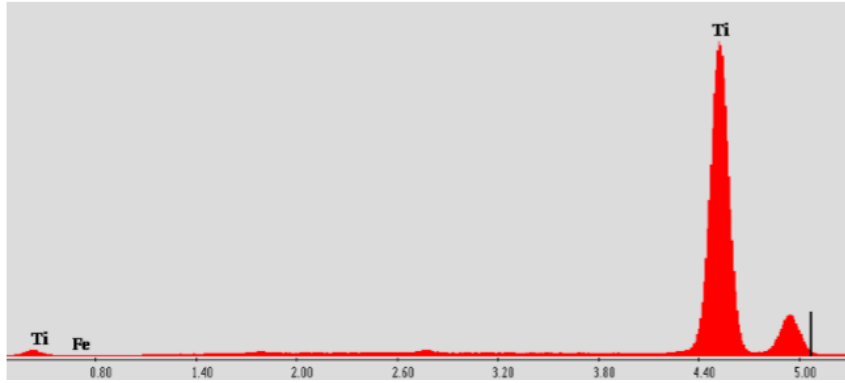

(c)

Figure 15 Sample 3: a) a low magnification SEM image of region $A$ and $B$ b) a high magnification SEM image of region A c) EDS analysis confirming presence of Ti in the consolidated region.

From the experimental evidence presented so far, it appears that FSP is, overall, an efficient process for consolidating Ti-powder and drastically improving the hardness of the final Ti-product.

\subsection{EBSD Analysis}

The EBSD analysis was performed on Sample 3 (Region A) to obtain information on grain morphology. The orientation image micrograph is shown in Figure 16. It shows equiaxed morphology of grains in FSP assisted consolidated region. Each color associated with the grains in the EBSD image represents a crystallographic axis perpendicular to the plane of the paper about which the information can be inferred from the inverse pole figure given in Figure 16. The average grain size was found to be $440 \mathrm{~nm}$ with a standard deviation of $254 \mathrm{~nm}$. Small grain size is a result of severe plastic deformation of Ti powder during consolidation using FSP. Thus, the refined small grain size can partly explain very high hardness observed for $\mathrm{Ti}$ in the consolidated region (Figures 9-11).

The SEM results in Figures 13 - 15 and the EBSD results included in Figure 16 showed the presence of no porosity and dynamically recrystallized grains. It is well established in FSP literature that the material goes through dynamic recrystallization process in the immediate vicinity of the FSP tool due to very high temperature and extensive plastic deformation (R. S. Mishra et al. 2014; S. Mironov et al., 2017). It, therefore, appears that processing parameters were sufficient enough to cause full consolidation of the Tipowder and fully consolidated material went through dynamic recrystallization process to lead to the grain structure shown in Figure 16.

Future goal is to allow titanium to be used for more than just aircraft. Even though this study described the basis of the proposed titanium production steps, later production will involve complex molds for the FSW to make usable components, and with a few runs of the machine over the area, it is hoped that the mechanical properties of the consolidated titanium can be controlled and then further improved for many applications.

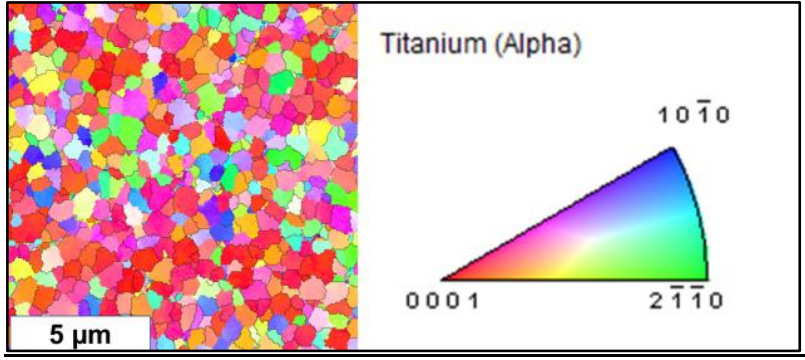

Figure 16 - EBSD micrograph for sample 3.

Future studies can look into variation of powder size and composition, tungsten and other tools with features, using titanium sample holder blocks, alloying the titanium before compaction, alloying the titanium by using a gradient method, etc. The future work can be directed towards many industries with many extended applications from the consumer's products to air force industrial jets.

From the preliminary results presented thus far, it is evident that the FSP has potential of transforming the metal powder in to bulk solid form and reducing the number of steps involved in conventional PM technique. Clearly, in the present process, powder blending step was eliminated and cold compression step was less restrictive than that needed in conventional PM technique (requires high green density of the compacted powder particles). Although a lot of work needs to be done before full potential of FSP as a tool to consolidate powder in to bulk solid form can be realized from industrial application point of view, one application would be manufacturing of washers (which will require machining of the FSP consolidated powder) which requires small volume of the material. The feasibility demonstration study also suggests that more layers can be added to the previous layers to obtain a large volume of the processed material (like that in additive manufacturing). A large volume of material thus processed will enable us to carry out evaluation of mechanical properties that require in some cases large volume of materials for machining large test samples. A large volume of the material will also enable manufacturing of different types of engineering components.

\section{Conclusions}

This study confirms that the titanium powder can be mechanically compressed then consolidated in to bulk material resulting in a strong solid final product with increased hardness than the original hardness property of commercially pure titanium. The overall consolidated region of the best welds was between 1 $\mathrm{mm}$ and $2 \mathrm{~mm}$ deep while the trend remained: the thicker the processed/consolidated region, the longer the spiked hardness was throughout the region. The highest recorded hardness was $436 \mathrm{HV} 0.3$ found on sample 3 which according to the literature is 2 to 3 times higher than the recorded hardness for commercially pure titanium. The averages of the 
spiked regions of each sample were 245, 201, and 307 for sample 1, 2, and 3 respectively. The interfaces on both sides for all samples show relatively clean separation between the carbon steel die and the consolidated titanium region. Overall, FSP proved to be an efficient process for consolidating Ti-powder and drastically improving the hardness of the final $\mathrm{Ti}$ product.

\section{Acknowledgement}

Authors would like to thank College of Engineering at University of North Texas as well as Center for Friction Stir Processing and all its federal and industrial sponsors for funding this research study and making it possible. Authors also thank Ms. Leannah Nicholes for developing Masters thesis from this study.

\section{References}

Online link: http://www.britannica.com/ science/ titanium, last accessed May 2017.

S.M. El-Soudani, Properties and Selection of Powder Metallurgy Titanium and Its Alloys, Powder Metallurgy, Vol 7, ASM Handbook, ASM International, 2015, p 627-641.

Online Link: https://www.youtube.com/ watch? v=41yjeguApo4, last accessed May 2017.

C. Doblin, D. Freeman, M. Richards, The TiRO ${ }^{\mathrm{TM}}$ process for the continuous direct production of titanium powder, Key Eng. Mater. Vol. 551 pp. 37-43, 2013.

G. M. D. Cantin, P. L. Kean, N. A. Stone, R. Wilson, M. A. Gibson, M. Yousuff, D. Ritchie, R. Rajakumar, Innovative consolidation of titanium and titanium alloy powders by direct rolling, Powder Metall. Vol. 54 pp. 188-192, 2011.

V. P. Katashinskii, G. A. Vinogradov, N. V. Rukhailo, G. Y. Kalutskii, Effects of particle size on the conditions of the strip shaping process in powder rolling - part II, Sov. Powder Metall. Metal Ceram. Vol. 14, Issue 11, pp. 883887, 1975.

Y. N. Podrezov, V. A. Nazarenko, A. V. Laptev, A. I. Tolochin, V. I. Danilenko, O. S. Koryak, Y. I. Evich, Mechanical properties of powder titanium at different production stages. IV. Mechanical properties and contact formation in powder titanium produced by dynamic hot pressing, Powder Metall. Metal Ceram. Vol. 48, pp. 295-301, 2009.
R. K. Dube, Metal strip via roll compaction and related powder metallurgy routes, Int. Mater. Rev. Vol. 35, Issue 5, pp. 253-291, 1990.

J. M. Rowe, J. R. Crison, T. J. Carragher, N. Vatsaraj, R. J. McCann, F. Nikfar, Mechanistic insights into the scale-up of the roller compaction process: a practical and dimensionless approach, J. Pharmaceut. Sci. Vol. 102, pp. 3586-3595, 2013.

K. A. Gogaev, V. A. Nazarenko, V. A. Voropaev, Y. N. Podrezov, D. G. Verbilo, O. S. Koryak, I. Y. Okun, Mechanical properties of powder titanium at different production stages. $\mathrm{V}$. Properties of a titanium strip produced by powder rolling Powder Metall. Metal Ceram. Vol. 48, pp. 652-658, 2009.

W. J. Kim, S. J. Yoo, H. T. Jeong, D. M. Kim, B. H. Choe, J. B. Lee Effect of the speed ratio on grain refinement and texture development in pure Ti during differential speed rolling, Scripta Mater. Vol. 64, pp. 49-52, 2011.

X. Huang, K. Suzuki, Y. Chino, Improvement of stretch formability of pure titanium sheet by differential speed rolling, Scripta Mater. Vol. 63, pp. 473-476, 2010.

R. S. Mishra, P. S. De, N. Kumar, Friction Stir Welding and Processing: Science and Engineering, Springer, 2014.

R. S. Mishra, Z. Y. Ma. Friction stir welding and processing. Mater. Sci. Eng. R. Vol. 50(1), pp. 1-78, 2005.

Z. Y. Ma. Friction stir processing technology: a review. Metall. Mater. Trans. A, Vol. 39(3), pp.642-658, 2008.

W.T. Evans, B. T. Gibson, J. T. Reynolds, A. M. Strauss, and G. E. Cook. Friction stir extrusion: a new process for joining dissimilar materials. Manuf. Lett. Vol. 5, pp.25-28, 2015.

W. T. Evans, G. E. Cook, and A. M. Strauss. Joining Aerospace Aluminum 2024-T4 to Titanium by Friction Stir Extrusion. In Friction Stir Welding and Processing IX (pp. 79-89). Springer International Publishing, 2017.

Online link: ASTM Handbook for Validity of Mechanical Testing, last accessed May 2017.

Online link: http://www.engineershandbook.com/ Tables/ hardness.htm, last accessed May 2017.

S. Mironov, Y. S. Sato, and H. Kokawa. Friction-stir welding and processing of $\mathrm{Ti}-6 \mathrm{Al}-4 \mathrm{~V}$ titanium alloy: A review. Journal of Materials Science \& Technology, in press, 2017 (DOI: https://doi.org/10.1016/j.jmst.2017.10.018). 